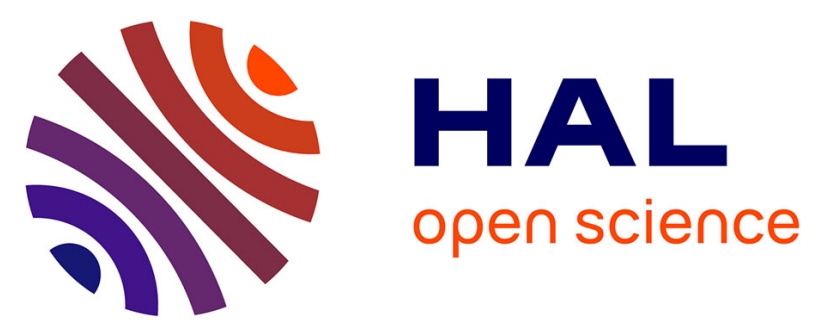

\title{
SAXS investigation of the effect of temperature on the multiscale structure of a macroporous poly $(\mathrm{N}$-isopropylacrylamide) gel
}

Mohand Chalal, Françoise Ehrburger-Dolle, Isabelle Morfin, Françoise Bley, Maria-Rosa Aguilar de Armas, María-Luisa López Donaire, Julio San Roman, Nimet Bölgen, Erhan Pişkin, Omar Ziane, et al.

\section{To cite this version:}

Mohand Chalal, Françoise Ehrburger-Dolle, Isabelle Morfin, Françoise Bley, Maria-Rosa Aguilar de Armas, et al.. SAXS investigation of the effect of temperature on the multiscale structure of a macroporous poly(N-isopropylacrylamide) gel. Macromolecules, 2010, Macromolecules, 43 (4), pp.2009 2017. 10.1021/ma902655h . hal-01086990

\section{HAL Id: hal-01086990 https://hal.science/hal-01086990}

Submitted on 25 Nov 2014

HAL is a multi-disciplinary open access archive for the deposit and dissemination of scientific research documents, whether they are published or not. The documents may come from teaching and research institutions in France or abroad, or from public or private research centers.
L'archive ouverte pluridisciplinaire HAL, est destinée au dépôt et à la diffusion de documents scientifiques de niveau recherche, publiés ou non, émanant des établissements d'enseignement et de recherche français ou étrangers, des laboratoires publics ou privés. 
SAXS investigation of the effect of temperature on the multiscale structure of a macroporous poly( $\mathrm{N}$-isopropylacrylamide) gel

Mohand Chalal $^{\text {a,b }}$, Françoise Ehrburger-Dolle ${ }^{a *}$, Isabelle Morfin ${ }^{a}$, Françoise Bley ${ }^{\mathrm{c}}$, MariaRosa Aguilar de Armas ${ }^{d}$, María-Luisa López Donaire ${ }^{d}$, Julio San Roman ${ }^{d}$, Nimet Bölgen ${ }^{\text {ex }}$, Erhan Pişkin ${ }^{\mathrm{e}}$, Omar Ziane ${ }^{\mathrm{b}}$, Roger Casalegno ${ }^{\mathrm{a}}$

${ }^{a}$ Laboratoire de Spectrométrie Physique, UMR 5588 CNRS-UJF, 38402 Saint Martin d'Hères, France

${ }^{b}$ Laboratoire d'Electronique Quantique, Faculté de Physique, USTHB, El-Alia Bab-Ezzouar, 16111 Alger and Département de Physique, Faculté des Sciences, UMBB, 35000 Boumerdès, Algeria

${ }^{c}$ Science et Ingénierie des Matériaux et Procédés, UMR5266 CNRS-UJF-INPG, 38402 SaintMartin d'Hères, France

${ }^{d}$ Instituto de Ciencia y Tecnología de Polímeros, CSIC and CIBER-BBN, C/ Juan de la Cierva, 3, 28006 Madrid, Spain

${ }^{e}$ Hacettepe University, Chemical Engineering Department and Bioengineering Division, Beytepe, Ankara, Turkey

ABSTRACT. The temperature induced structural modifications of poly( $N$-isopropylacrylamide $)$ hydrogel (pNIPA) were investigated by Small-Angle X-ray Scattering (SAXS) over a broad range of $q$-values $\left(3.5 \times 10^{-2}-12 \mathrm{~nm}^{-1}\right)$ at temperatures ranging between 18 and $37^{\circ} \mathrm{C}$. The sample studied was elaborated by cryopolymerization yielding a macroporous gel (cryogel). The pNIPA gel forms the walls (the thickness at $23^{\circ} \mathrm{C}$ is about $12 \mu \mathrm{m}$ ). The SAXS curves display an isoscattering (or isosbestic) point located at $\mathrm{q}_{\mathrm{iso}}=3.633 \mathrm{~nm}^{-1}$ and disappearing above $30^{\circ} \mathrm{C}$. This feature has never been reported up to now. The SAXS curves obtained at each temperature are well fitted by a sum of four equations describing respectively the scattering resulting from the gel surface (power law), from the solid-like (Guinier equation) and liquid-like (Ornstein-Zernike equation) heterogeneities and from the chain-chain correlation yielding a broad peak (pseudo-Voigt equation) in the high- $q$ domain. The temperature dependence of the parameters obtained from the fit is analyzed and discussed.

Keywords: thermosensitive cryogel, pNIPA, SAXS, volume phase transition, isoscattering point.

\section{Introduction}

Poly( $N$-isopropylacrylamide) (pNIPAm) gel is a typical example of a temperature sensitive gel as it exhibits a volume phase transition at a critical temperature $(T \mathrm{c})$ of about $34{ }^{\circ} \mathrm{C}$ in aqueous media [1]. Below Tc, pNIPA hydrogels are swollen, hydrated, and hydrophilic. Above $T \mathrm{c}$, the gels shrink due to the distortion of the hydrophilic/hydrophobic balance in the network structure. The rate of

\footnotetext{
* Corresponding author; e-mail: fehrburg@ @ spectro.ujf-grenoble.fr
} 
response of pNIPA hydrogels is low due to the formation of a dense "skin layer" of the shrunken gel, which prevents the mass transport of water out of the shrinking gel [2]. One possibility to circumvent this problem inherent to macroscopic gels (or macrogels) is by decreasing the size of the gels to mesoscopic lengths. Thus a large amount of work dealing with synthesis and characterization of colloidal microgels has been published [3, 4]. An alternative way to accelerate the response of pNIPA gels consists in the synthesis of a macroporous gel [5]. The macropores serve as channels that facilitate convective transport of liquid released during the shrinkage of the gel constituting the thin macropore walls. An efficient way to obtain macroporous gels is the cryotropic gelation technique [6], implying polymerization at a sub-zero temperature, yielding cryogels. These highly porous polymeric materials exhibit a broad variety of porosities and morphologies [7-11] allowing the preparation of macroporous gels with properties tailored for a given application, particularly in the field of biochemistry or bioengineering (e.g., tissue engineering scaffolds [12]).

As information about the internal structure of the gels and its variation as a function of temperature is essential for using gels as functional materials, this field has been widely investigated since the last 30 years [13]. It appears that Small-Angle Scattering measurements [14] constitute experimental methods that are well adapted to investigate the multiscale structure of polymer gels. The usual $q$-domain for Small Angle X-ray Scattering (SAXS) or Small Angle Neutron Scattering SANS $\left(10^{-2}\right.$ to $\left.1 \mathrm{~nm}^{-1}\right)$ allowing structural information between roughly 100 and $1 \mathrm{~nm}$ in the real space can be extended up to a few $\mu \mathrm{m}$ by Small Angle Light Scattering (SALS) for transparent gels. The first extensive study of pNIPA gels (macrogels) near the volume phase transition by SANS was reported by Shibayama et al. in 1992 [15]. Since that time, several papers reporting SAXS or SANS studies of thermally induced structural modifications in pNIPA gels [16-20] have been published. Because of their fast kinetic response, microgels [21-22] or core-shell colloidal particles [23-24] were also extensively investigated. The first paper devoted to the comparison of SAXS curves obtained for macrogels and cryogels appeared recently [25]. It was shown that combining SAXS and Wide-Angle X-ray Scattering (WAXS) by extending the $q$-domain generally investigated (0.05 - $\left.1 \mathrm{~nm}^{-1}\right)$ up to larger $q$-values $\left(12 \mathrm{~nm}^{-1}\right)$ brings new information about the changes in the molecular arrangement below and above the transition temperature.

The aim of the present paper is to show the structural modifications occurring during the stepwise increase of temperature not only at the mesoscale but also, for the first time, at the molecular scale. The choice of a macroporous gel for this study offers the possibility to investigate a thermosensitive gel having a relatively small thickness (a few micrometers) yet larger than microgels (a few

× Present address: Mersin University, Faculty of Engineering, Department of Chemical Engineering Çiftlikköy, 33343 , Mersin, Turkey 
hundred nanometers) but without the need for stabilization of colloidal particles. The macroscopic structure (macropore size distribution and wall thickness) of this cryogel and its change with temperature have been investigated previously by Two-Photon Fluorescence Microscopy [26]. The wall thickness (i.e., the thickness of the gel investigated here by SAXS) was shown to decrease from $12 \pm 2 \mu \mathrm{m}$ at $23^{\circ} \mathrm{C}$ to $10 \pm 2 \mu \mathrm{m}$ at $28^{\circ} \mathrm{C}$ and to $4 \mu \mathrm{m}$ at $34^{\circ} \mathrm{C}$. The present paper is devoted to the study of the internal structure of these walls, at the meso and nanoscale at different temperatures between 18 and $37^{\circ} \mathrm{C}$. The observed features will be related to that occurring at the macroscopic scale.

\section{Materials and experimental method}

2.1. Cryogel sample preparation. The pNIPA cryogel was prepared in tubular-shaped glass molds $(0.5 \mathrm{~cm}$ diameter) by free radical polymerization. The total monomer (NIPA) concentration within the medium (distilled water) was $6 \% \mathrm{wt} / \mathrm{v}$. The amount of cross-linker, N,N'methylenebisacrylamide (MBAA), was $6.6 \mathrm{wt} \%$ of the total amount NIPA, corresponding to $1 \mathrm{M}$ for $15 \mathrm{M}$ of NIPA yielding a degree of cross-linking larger than for the pNIPA cryogel we have investigated previously (1/40 in ref. [25]) and for the gel investigated by Shibayama et al. [16]. Nitrogen was passed-through the solution for 15 min prior to polymerization. For reaction activation, $\mathrm{N}, \mathrm{N}, \mathrm{N}^{\prime}, \mathrm{N}^{\prime}-$-Tetramethylethylenediamine (TEMED) (1 wt $\%$ ) was added and the solution was cooled in an ice bath for $5 \mathrm{~min}$. Then the radical initiator, ammonium persulfate (APS) ( $1 \mathrm{wt} \%)$, was added and the reaction mixture was stirred during about 1 minute. $1 \mathrm{ml}$ of the reaction mixture was injected into each glass mold. Extensive details of the cryogelation (or cryopolymerization) are given elsewhere [25]. The solution in the mold was frozen at $-20^{\circ} \mathrm{C}$ in about $1 \mathrm{~h}$ in order to attain the polymerization reaction conditions $\left(-12^{\circ} \mathrm{C}\right)$ as fast as possible for avoiding polymerization to begin before of all components were frozen. Chemical polymerization starts at $-20^{\circ} \mathrm{C}$ and completes during storage of the sample at $-12^{\circ} \mathrm{C}$ for 16 hours. The sample was subsequently thawed at room temperature. The yield of the polymerization reactions generally exceeds $85 \%$. The cryogel matrix in the glass mold was washed by passing distilled water to remove any possible unreacted monomers and other ingredients and dried in air until to reach a constant weight. Re-swelling of the dry cryogel in water occurs within a few minutes [11].

2.2. SAXS measurements. SAXS experiments were performed at the European Synchrotron Radiation Facility (ESRF) ${ }^{\text {a }}$ Grenoble, France on the French CRG beamline D2AM. The incident energy was set to $16 \mathrm{keV}(\lambda=0.77 \AA$ ). The detector, an indirect illumination CCD camera (Princeton Instruments), with pixel size equal to $50 \mu \mathrm{m}$ was located at distances of 2 and $0.3 \mathrm{~m}$

\footnotetext{
${ }^{\mathrm{a}}$ http://www.esrf.eu/
} 
from the sample. These configurations provided data for wave vectors $q\left(q=\left(\frac{4 \pi}{\lambda}\right) \sin \left(\frac{\theta}{2}\right)\right)$ ranging between $3.5 \times 10^{-2}$ and $12 \mathrm{~nm}^{-1}$. The beam-stop was a small pillar ( $2 \mathrm{~mm}$ diameter lead wire). The swollen sample was placed in a stainless steel holder closed by two mica windows $1 \mathrm{~mm}$ apart. The sample holder was inserted in a small furnace allowing temperature to vary between 10 and $40^{\circ} \mathrm{C}$ with an accuracy better than $0.2^{\circ} \mathrm{C}$. Heating was provided by a Thermocoax ${ }^{\circledR}$ wire coiled around the furnace concentrically to a cold water circuit. Temperature control was achieved by means of an Eurotherm ${ }^{\circledR}$ controller and sample temperature was measured by a Pt resistance located close to the cryogel sample. SAXS measurements were performed at 9 temperatures $(18,21,24,26,28,30,32$, 34 and $37^{\circ} \mathrm{C}$ ). The duration of each temperature plateau was 16 minutes. After about 8 minutes, the shape of the curves did not change anymore as equilibrium was reached. Temperature control and data acquisition were automated. The images were processed by means of the software $b m 2 \mathrm{img}$ available on the beamline ${ }^{\mathrm{b}}$. All intensity curves were corrected by taking into account the flat field and the dark current. Scattering of the same thickness of pure water was subtracted from the total intensity.

\section{Results and Discussion}

3.1. Evolution of the SAXS curves with temperature. Figure 1 shows the double logarithmic plots of the SAXS intensity $I(q)$ obtained for the cryogel at the different temperatures. The curve (arbitrarily shifted along the intensity axis) obtained for the dry cryogel is also plotted in Figure 1. The comparison between the latter and the curves obtained for the swollen sample below $\left(\mathrm{T}=18^{\circ} \mathrm{C}\right)$ and above $\left(\mathrm{T}=37^{\circ} \mathrm{C}\right)$ the transition temperature, reveals the same trends as previously reported for other series of cryogels [25]: a strong increase of the high- $q$ correlation peak which appears as a bump at low temperature as in gels $[19,25]$ and a significant decrease of the scattered intensity in the intermediate $q$ domain above $30^{\circ} \mathrm{C}$. For the dry sample, the intensity scattered in the low- $q$ region is much larger than for the collapsed hydrogel. This feature reveals the macroscopic collapse after drying yielding a strong increase of the wall surface per unit volume. These questions will be discussed in details in the next paragraphs. The interesting feature shown in this figure is the existence of an isoscattering point more clearly seen in the insert. This point, located at $\mathrm{q}_{\text {iso }}=3.633$ $\mathrm{nm}^{-1}$ and vanishing above $30^{\circ} \mathrm{C}$ was never mentioned before as this $q$-domain was never investigated. Isoscattering points have been reported in several phase change processes driven by temperature as the smectic $\mathrm{C}$ to smectic A transition in liquid crystals [27], the isothermal crystallization of cocoa butter between 19 and $23^{\circ} \mathrm{C}$ [28] and more generally in microphase

\footnotetext{
${ }^{\mathrm{b}}$ http://www.esrf.fr/exp_facilities/BM2/BM2.html
} 
separation processes [29-31]. The origin of the isoscattering point observed here will be discussed in a next paragraph.

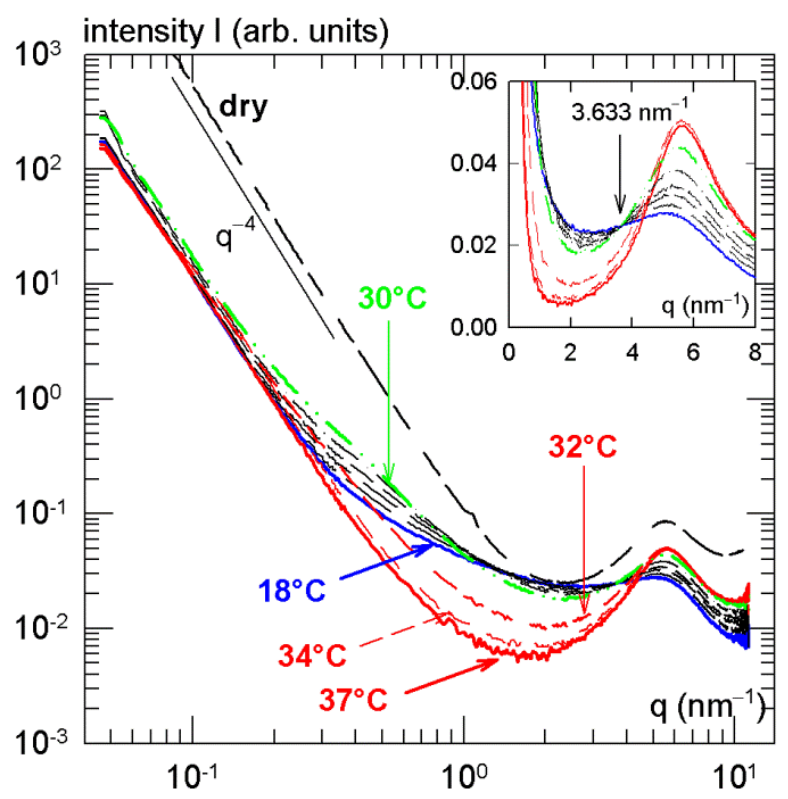

Figure 1. Evolution of the SAXS curves with temperature and comparison with the curve obtained for the dry cryogel for which the intensity was arbitrarily shifted. The insert shows the curves plotted in linear coordinates displaying an isoscattering point $(I=0.0245 \pm 0.0002)$ located at $3.633 \pm 0.012 \mathrm{~nm}^{-1}$.

3.2 Scattering functions and fitting of the experimental curves. In the $q$ domain investigated by a large majority of researchers $\left(q<1 \mathrm{~nm}^{-1}\right)$, small-angle scattering of neutrons (SANS) or X-rays (SAXS) by neutral gels is assumed to result from the sum of two contributions [15]:

- the scattering from density fluctuations which exist also in semi-dilute polymer solutions (liquidlike or solutionlike fluctuations) and which are described by the Ornstein-Zernike (OZ) equation

$$
I_{\mathrm{OZ}}(q)=\frac{I_{\mathrm{OZ}}(0)}{1+q^{2} \xi^{2}}
$$

where $\xi$ is the correlation length; $\xi$ represents the range of the spatial correlation of concentration fluctuations in the gel (polymer rich domains) that will be named T-blobs in the following as they depend on temperature; $I_{\mathrm{OZ}}(0)$ is the asymptotic value of the $\mathrm{O}-\mathrm{Z}$ intensity when $q \rightarrow 0$ - the scattering from solidlike density fluctuation due to the gel cross-linking often described by a Guinier equation

$$
I_{\mathrm{G}}(q)=I_{\mathrm{G}}(0) \exp \left[-\frac{R_{\mathrm{G}}^{2} q^{2}}{3}\right]
$$


where $R_{\mathrm{G}}$ is the Guinier radius of gyration related to the diameter $a$ by $a=2 R_{G} \sqrt{5 / 3}$ for spherical objects and $I_{\mathrm{G}}(0)$ is the asymptotic value of the Guinier intensity when $q \rightarrow 0$.

In the present case, experiments were extended in the WAXS domain in order to investigate the chain-chain correlation peak recently revealed in cryogels and gels [25]. Without the support of a relevant model, such peaks can be fitted with a pseudo-Voigt equation [27] writing as

$$
I_{\mathrm{V}}(q)=a\left[\frac{c}{1+\left(q-q_{1}\right)^{2} \xi_{1}^{2}}+(1-c) \exp \left(-\frac{\left(q-q_{1}\right)^{2} \xi_{1}^{2}}{2}\right)\right]
$$

where $a$ corresponds to the maximum of the peak located at $q_{1}$ (assumed to correspond to $d=2 \pi / q_{1}$ in the real space), $c$ is the fraction of the lorentzian contribution and $\xi_{1}$ is related to the size of the organized domains.

Finally, because the gel objects investigated are the walls ( $12 \mu \mathrm{m}$ thick at room temperature) of the macropores, a low- $q$ intensity turn-up resulting from the scattering of the gel surface is expected and actually observed. Thus, the low- $q$ part of the intensity curve $\mathrm{I}(q)$ will be described by the following power law

$$
I_{\mathrm{P}}(q)=I_{\mathrm{P}_{0}} q^{-p}
$$

where the exponent $p$ is related to the surface fractal dimension $D_{\mathrm{s}}$ by $D_{s}=6-p$ and $I_{\mathrm{P}_{0}}$ is the prefactor.

It follows that the equation $I_{f i t}(q)$ used for the fit of the experimental curve $I(q)$ consists in the sum of four equations

$$
I_{f i t}(q)=I_{\mathrm{P}}(q)+I_{\mathrm{G}}(q)+I_{\mathrm{OZ}}(q)+I_{\mathrm{V}}(q)
$$

involving 10 parameters in a non-linear regression. The regression procedure was achieved by means of the Marquardt-Levenberg algorithm provided by SigmaPlot 10.0. Because the data in $I(q)$ extend over more than 4 decades, a weight $w=1 /[I(q)]^{2}$ was used. The upper $q$ limit for the regression was fixed at $6.2 \mathrm{~nm}^{-1}$ in order to avoid the contribution of expected scattering features occurring at higher $q$-values. Figure 2 shows, as an example, the result of the fit for the intensity curve measured at $28^{\circ} \mathrm{C}$. The variation of the residuals as a function of $q$ is also plotted (insert). As shown in the second insert, the residual distribution is gaussian and the peak is located very near zero $\left(9.11 \times 10^{-5}\right)$ and its half-width equals 0.01 . A linear regression of the variation of the predicted versus measured intensity (not shown) yields a slope equal to 1.006 and extrapolates to -0.012 $\left(r^{2}=0.9998\right)$. The same analysis of the fit results was performed for all experimental curves and 
yielded similar conclusions. The value of the parameters, the statistical errors and the dependencies obtained for the above fit are indicated in Table 1.

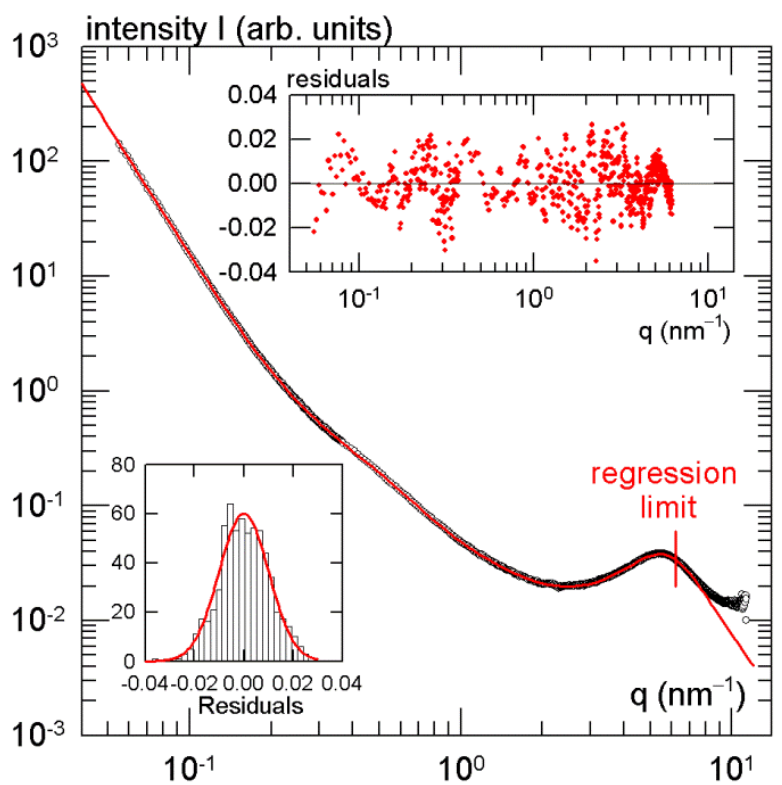

Figure 2. Fit of the experimental data obtained at $28^{\circ} \mathrm{C}$ with equation (5). The parameters extracted from the fit are given in Table 1. The upper insert shows the variation of the residuals with $q$. Their distribution is shown in the lower insert. The red line is the fit of the residuals with a Gaussian distribution $\left(\mathrm{r}^{2}=0.963\right)$. The position of the maximum is equal to $9.12 \mathrm{e}-5$.

As expected in a regression with four equations and ten parameters, it is essential to avoid incorrect solutions resulting from a local minimum in the sum of squares. To this end, firstly, a very small tolerance value must be used: in the present case tolerance was set to $10^{-20}$. Secondly, the initial parameters were modified until a solution yielding not only a good regression coefficient $\left(\mathrm{r}^{2}\right.$ close to 0.999 ) but also dependencies that are all strictly smaller than 1. It was shown, by changing the value of the initial parameters, that the solution with dependencies strictly smaller than 1 is unique. Thus the fitting equation obtained by the non-linear regression can be considered as describing satisfactorily the experimental data and the analysis of the extracted parameters presented in the next paragraph will make sense. 


\begin{tabular}{lcccc}
\hline Parameter & Value & Standard Error & CV $(\%)^{\mathrm{a}}$ & Dependency $^{\mathrm{b}}$ \\
\hline $\mathrm{I}_{\mathrm{p} 0}$ & $2.67 \times 10^{-3}$ & $0.04 \times 10^{-3}$ & 1.42 & 0.994 \\
$\mathrm{p}$ & 3.755 & 0.006 & 0.15 & 0.998 \\
$\mathrm{I}_{\mathrm{G}}(0)$ & 0.142 & 0.009 & 6.29 & 0.992 \\
$\mathrm{R}_{\mathrm{G}}(\mathrm{nm})$ & 3.89 & 0.04 & 0.96 & 0.922 \\
$\mathrm{I}_{\mathrm{OZ}}(0)$ & 0.32 & 0.02 & 6.37 & 0.999 \\
$\xi(\mathrm{nm})$ & 2.7 & 0.1 & 3.72 & 0.999 \\
$a$ & $3.657 \times 10^{-2}$ & $0.004 \times 10^{-2}$ & 0.11 & 0.693 \\
$\mathrm{c}$ & 1.00 & 0.03 & 3.18 & 0.974 \\
$\mathrm{q}_{1}\left(\mathrm{~nm}{ }^{-1}\right)$ & 5.477 & 0.005 & 0.09 & 0.855 \\
$\xi_{1}(\mathrm{~nm})$ & 0.452 & 0.004 & 0.77 & 0.986 \\
\hline
\end{tabular}

${ }^{\mathrm{a}} \mathrm{CV}(\%)$ is the parameter coefficients of variation, expressed as a percentage. This is the normalized version of the standard errors: $C V=$ Standard Error $\times 100$ /parameter value.

${ }^{\mathrm{b}}$ The dependence of a parameter is defined to be:

dependency $=1-\frac{\text { variance of the parameter, other parameters constant }}{\text { variance of the parameter, other parameters changing }}$

Table 1. Value of the parameters obtained by fitting the experimental curve at $28^{\circ} \mathrm{C}$ with equation (5). The regression procedure was achieved by means of the Marquardt-Levenberg algorithm provided by SigmaPlot 10.0 (www.systat.com ). A weight $w=1 /[I(q)]^{2}$ was used and tolerance was set to $10^{-20}$. The regression coefficient $r^{2}$ is equal to 0.9997 .

For the pseudo-Voigt equation $c$ equals 1 . It means that the distribution is lorentzian. In fact, in most cases, $c$ remains equal or close to unity. Thus this parameter will not be discussed in the following. Figure 3 shows logarithmic plots of the curves calculated with the parameters extracted from the fits at different temperatures. It appears that the contribution of the Ornstein-Zernike scattering extends over a very broad range of $q$ values. This feature affects the contribution of all other regimes yielding a dependency larger for the $\mathrm{OZ}$ parameters than for the other ones and, therefore, a larger statistical error (see Table 1). This observation also explains the failure of attempts aiming to reduce the number of parameters by performing fits over a restricted range of $q$ values (up to $1 \mathrm{~nm}^{-1}$, corresponding to the experimental conditions of ref. [15]). 

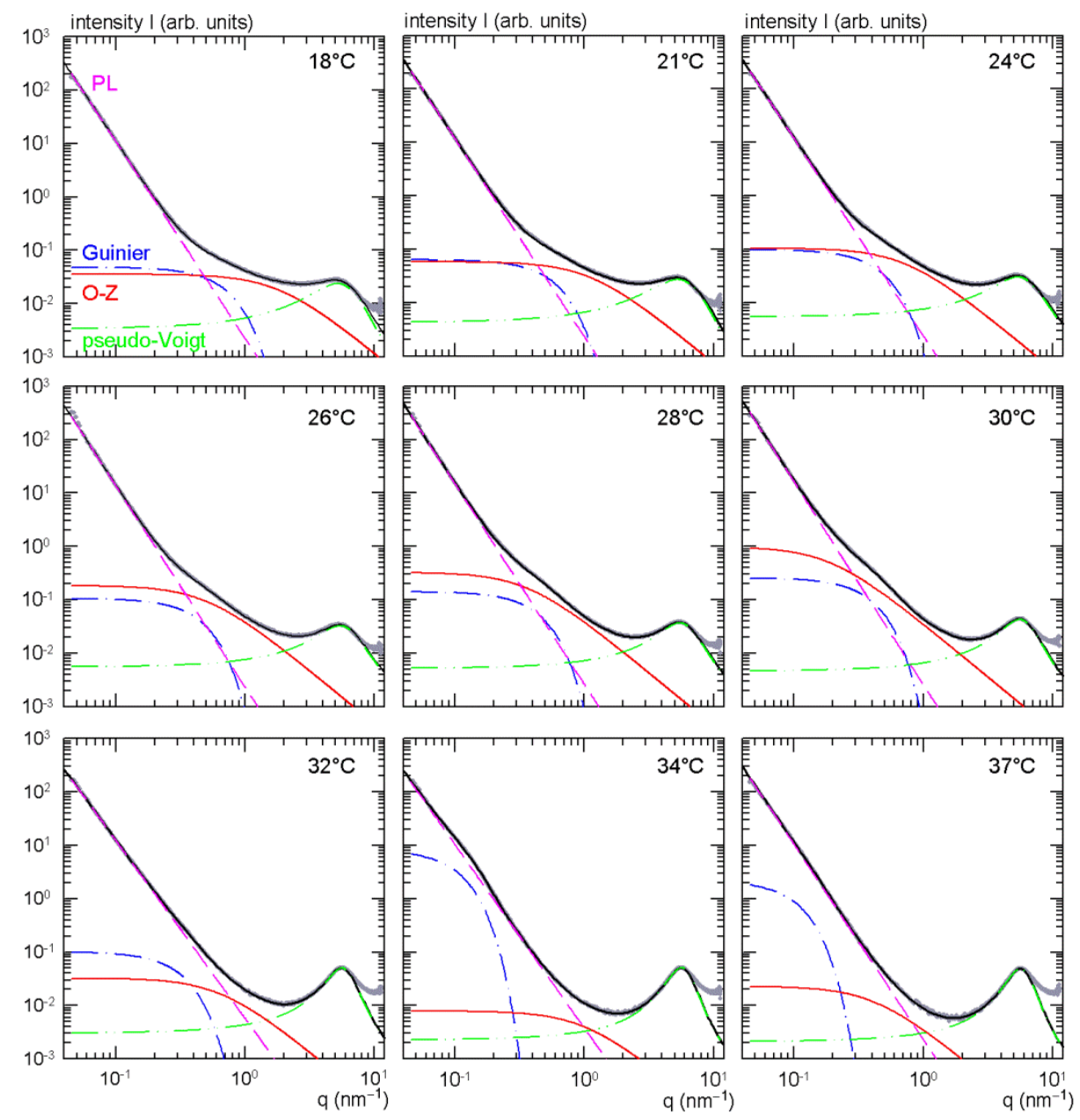

Figure 3. Logarithmic plots of the four curves contributing to the fit (black continuous line) of the experimental data (dark grey circles) and calculated by using the fitting parameters.

The evolution with temperature of the $\mathrm{OZ}$ and pseudo-Voigt calculated curves is shown on Figures $4 \mathrm{a}$ and $4 \mathrm{~b}$. Below $32^{\circ} \mathrm{C}$ (Figure $4 \mathrm{a}$ ), the intensity of the chain-chain correlation peak increases. Above $32^{\circ} \mathrm{C}$ (Figure 4b), the $\mathrm{OZ}$ contribution drops significantly while the peak remains nearly unchanged and similar to that obtained for the dry cryogel as already observed previously in other cryogels [25]. Figure 4c shows the sum of the OZ and pseudo-Voigt curves calculated from the fit. These curves display (see insert) the same isoscattering point as the experimental curves plotted in Figure 1. This result strengthens the validity of the fitting procedure and proves that the isoscattering point is related to the structure of the T-blobs. Actually, such a result is also expected from the curves plotted in Figure 3 which show that the power law and the Guinier scattering do not contribute anymore to the intensity in the isoscattering point region. 


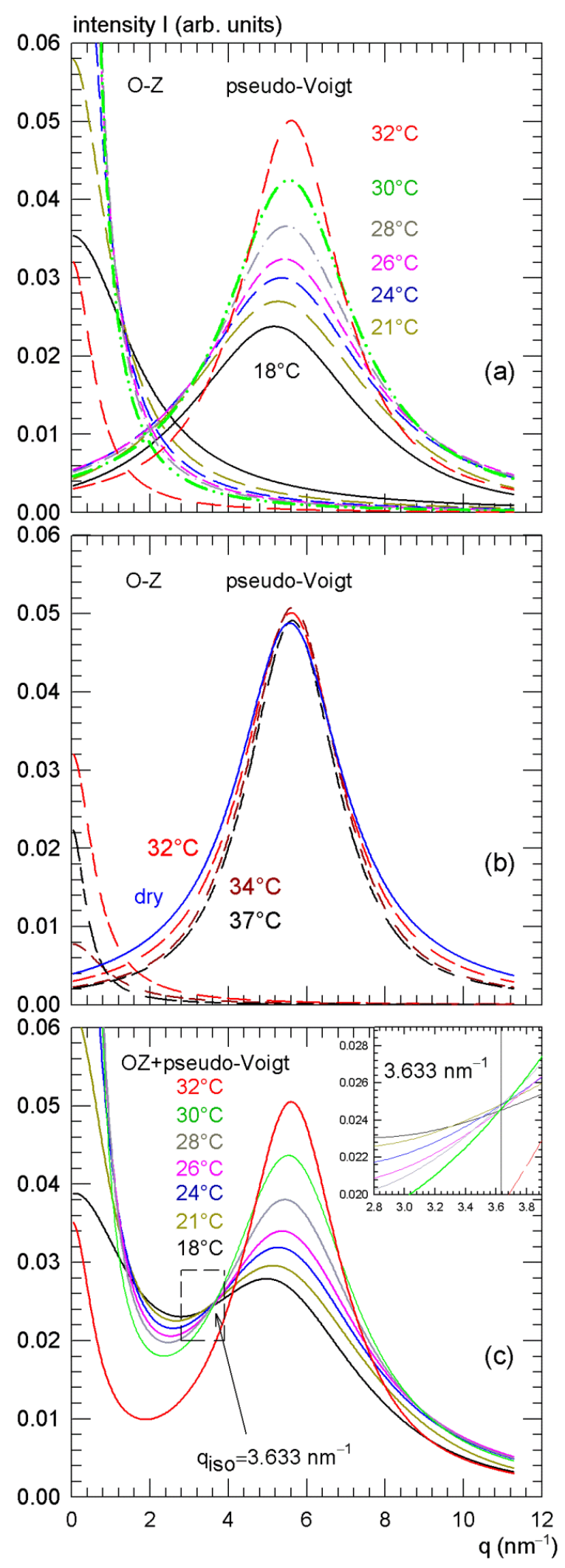

Figure 4. Evolution of the Ornstein-Zernike and the pseudo-Voigt curves calculated by using the parameters obtained from the fit (a) between 18 and $32^{\circ} \mathrm{C}$; (b) at 32,34 and $37^{\circ} \mathrm{C}$ and for the dry cryogel; (c) sum of the O-Z and Voigt curves displaying the same isoscattering point (insert) as the experimental curves. 
3.3. Analysis of the parameters. Figure 5 shows the variation of the $\mathrm{OZ}$ parameters $\xi$ and $I_{\mathrm{OZ}}(0)$ defined in Equation (1). In a phase transition, both parameters are expected to diverge at a critical temperature $T_{c}$ according to the following equations, near $T_{c}$ :

$$
\begin{aligned}
& \xi=A\left|T_{c}-T\right|^{-v} \\
& I_{\mathrm{OZ}}(0)=B\left|T_{c}-T\right|^{-\gamma}
\end{aligned}
$$

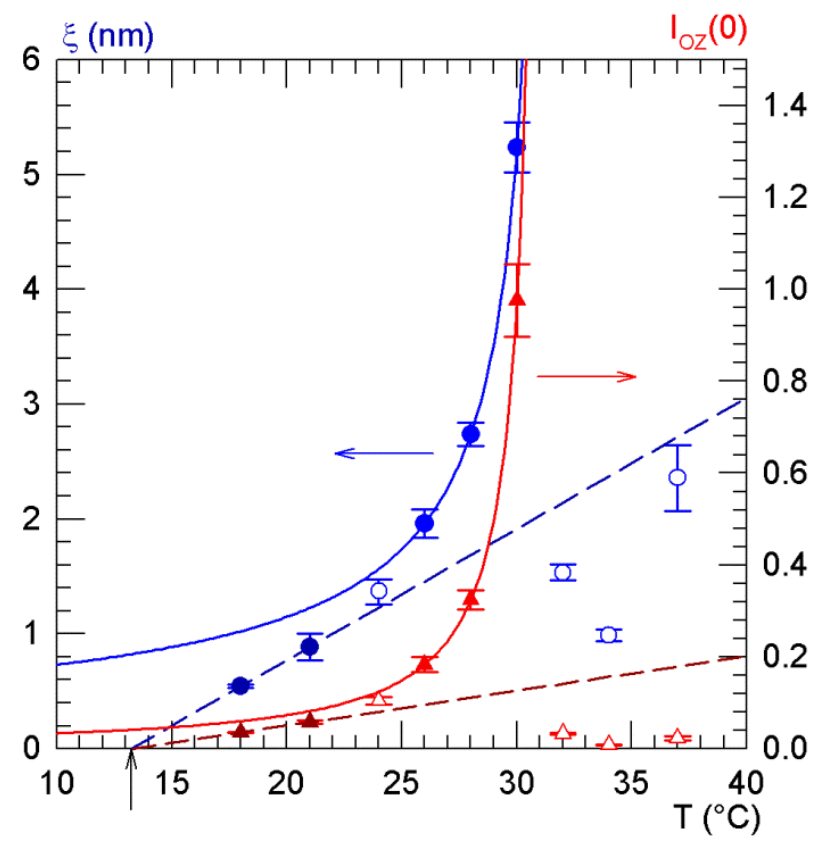

Figure 5. Variation of the correlation length $\xi$ (left axis) and the asymptotic intensity $I_{\mathrm{OZ}}(0)$ (right axis) with temperature. The solid lines result from the fit with equations (6) and (7). The dashed lines drawn through the points obtained at 18 and $21^{\circ} \mathrm{C}$ extrapolate to $13.3^{\circ} \mathrm{C}$ (arrow).

By means of swelling and calorimetry experiments, Li and Tanaka [32] have shown that pNIPA gels belong to the Ising universality class. In these conditions, one expects $v=0.631$ and $\gamma=1.238$. These exponents are slightly larger than the ones involved in the mean field model ( 0.5 and 1 for $v$ and $\gamma$ respectively). In any case, Equations (6) and (7) imply that $\xi$ scales as $\left[I_{\mathrm{OZ}}(0)\right]^{v / \gamma}$ with $v / \gamma$ close to 0.5 . This remark allows the determination of the temperature domain in which the fit to Equations (6) and (7) is relevant. As shown in Figure 6, this scaling law is verified only for three temperatures $\left(26,28\right.$ and $30^{\circ} \mathrm{C}$ ) yielding an exponent equal to 0.586 (may be four if the point at $24^{\circ} \mathrm{C}$ is taken into account) which is quite small. Nevertheless, a non-linear regression with Equations (6) and (7) performed over the three point yields (i), the same $\mathrm{T}_{\mathrm{c}}$ value (31.35 and 31.36 in Equations (6) and (7), respectively) and (ii), critical exponents $v=0.712$ and $\gamma=1.22$. Including the point at $24^{\circ} \mathrm{C}$ for the non-linear regression yields a significant difference between the values of 
$\mathrm{T}_{\mathrm{c}}$ obtained from the fit by equation $(6)\left(32.30^{\circ} \mathrm{C}\right)$ and equation $(7)\left(31.90^{\circ} \mathrm{C}\right)$, and unrealistic exponents $(v=1.015$ and $\gamma=1.523)$.

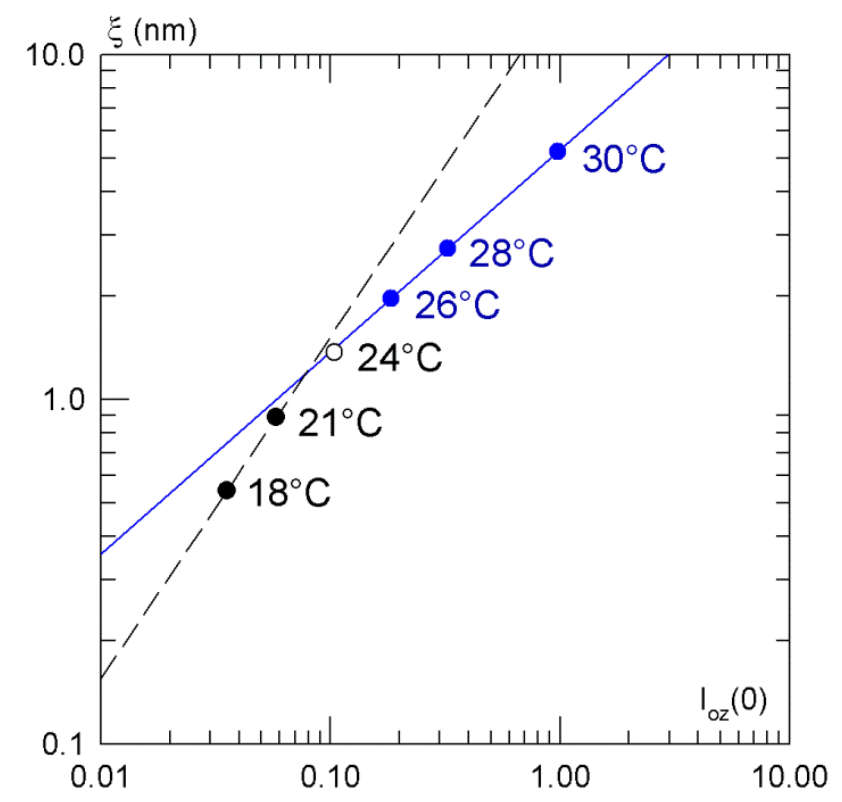

Figure 6. Logarithmic plot of the variation of the parameter $\xi$ with the $\mathrm{I}_{\mathrm{OZ}}(0)$. The solid line results from the linear regression $\left(r^{2}=0.9999991\right)$ of the data measured at 26,28 and $30^{\circ} \mathrm{C}$. The slope is equal to 0.586 . The slope of the dashed line joining the points at 18 and $21^{\circ} \mathrm{C}$ is equal to 0.99 .

Further, the critical temperature $\left(31.4^{\circ} \mathrm{C}\right)$ deduced from Differential Scanning Calorimetry (DSC) measurements (Figure 7) and resulting from the "melting" of the water cages around the isopropyl groups [33] agrees perfectly with that determined by the non-linear regression performed between 26 and $30^{\circ} \mathrm{C}$. Thus, despite the fact that the number of data points is very low, the result agrees with an Ising model for describing the transition in the present pNIPA cryogel as it was for the gels investigated by Shibayama [15], yet the value of $v$ is slightly larger than the theoretical one (0.631). It could be observed in Figure 5 that the lines drawn through the points corresponding to 18 and $21^{\circ} \mathrm{C}$ for $\xi$ and $I_{\mathrm{OZ}}(0)$ extrapolate to the same temperature $\left(13.3^{\circ} \mathrm{C}\right)$. Also, the slope of this line in the logarithmic plot of $\xi$ versus $I_{\mathrm{OZ}}(0)$ (Figure 6) is very close to 1 . These features do not prove a linear increase of $\xi$ and $I_{\mathrm{OZ}}(0)$ in the low temperature domain but incites one to further investigate this question in the future.

Equation (1) indicates that the intensity $I_{\mathrm{OZ}}(q)$ scale as $q^{-2}$ for $q \xi>1$, in the asymptotic regime. In fact, this asymptotic regime is not visible because of the high- $q$ extra scattering resulting from an inter-chain correlation revealed by the broad peak fitted with the pseudo-Voigt equation (Equation 3 ). The variation of the peak position $q_{1}$ and the peak height $a$ as a function of temperature are plotted on Figure 8. 


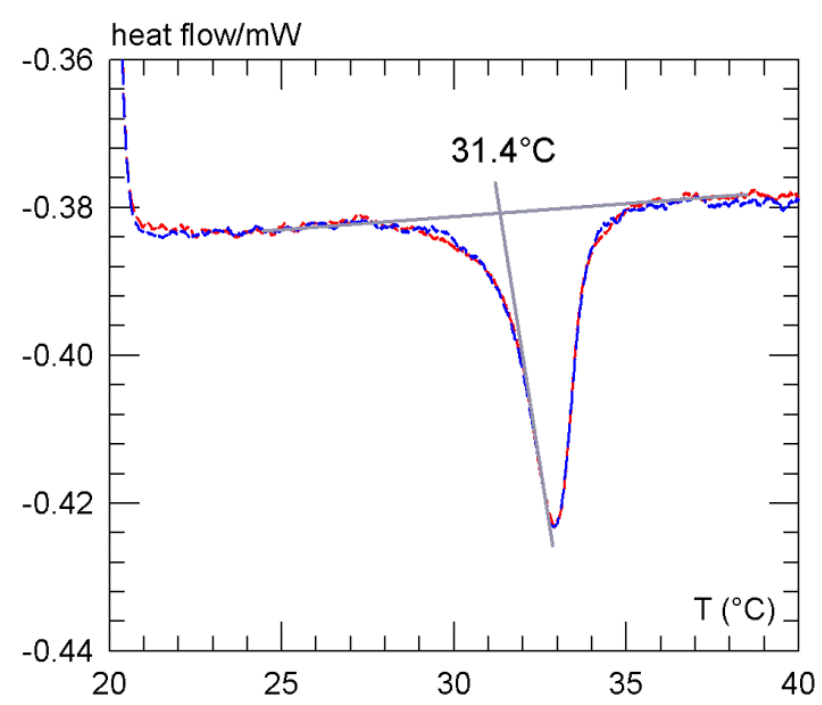

Figure 7. Differential Scanning Calorimetry (DSC) curves measured at a heating rate equal to $0.5^{\circ} \mathrm{C} / \mathrm{min}$ (SETARAM Micro DSC III).

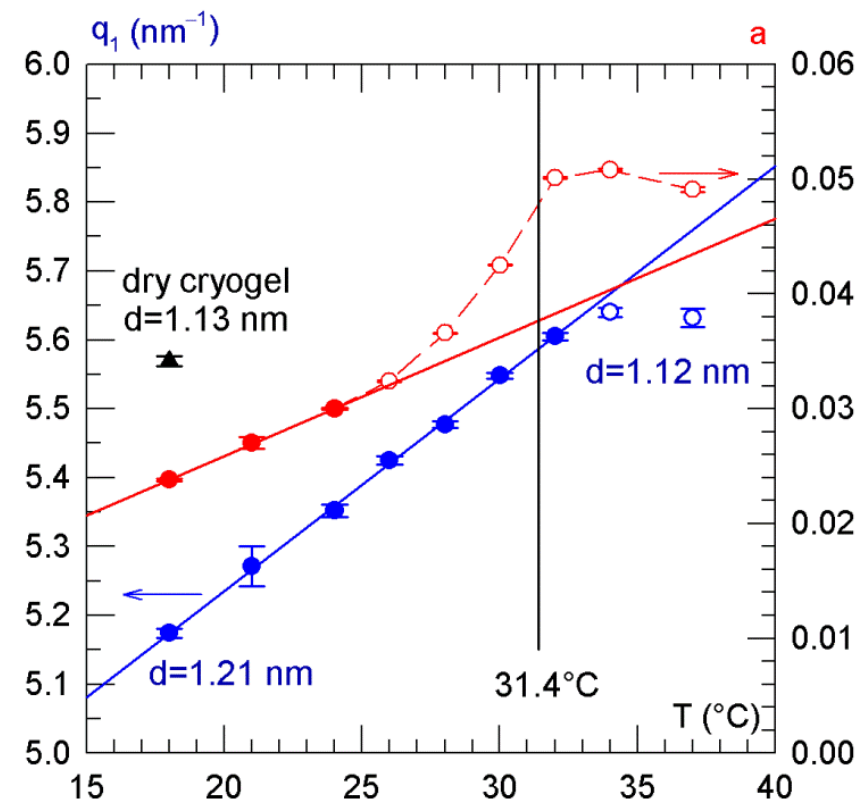

Figure 8. Evolution of the position $q_{1}$ (left axis) and the intensity $a$ (right axis) of the high- $q$ peak resulting from the fit with the pseudo-Voigt equation (Equation 3). The solid lines result from a linear regression of the data (closed symbols).

The two other parameters obtained from the fit of the peak with the pseudo-Voigt equation, i.e., $c$, the fraction of the Lorentzian versus Gaussian distribution and $\xi_{1}$, related to the extent of the organized domains, are plotted as a function of temperature in Figure 9. It appears that the overall fit is not very sensitive to $c$, as also suggested by large statistical errors. Thus, the variation of $c$ between 0.7 and 1 (pure Lorentzian distribution) with temperature may not be relevant. The same comment could apply to the variation of $\xi_{1}$ with temperature yet the increase of $\xi_{1}$ by a factor two may not be artifactual but this point will not be discussed further. In contrast with these two 
parameters, the peak position $q_{1}$ which can be easily checked without any fit and the peak height $a$ deserve further comments.

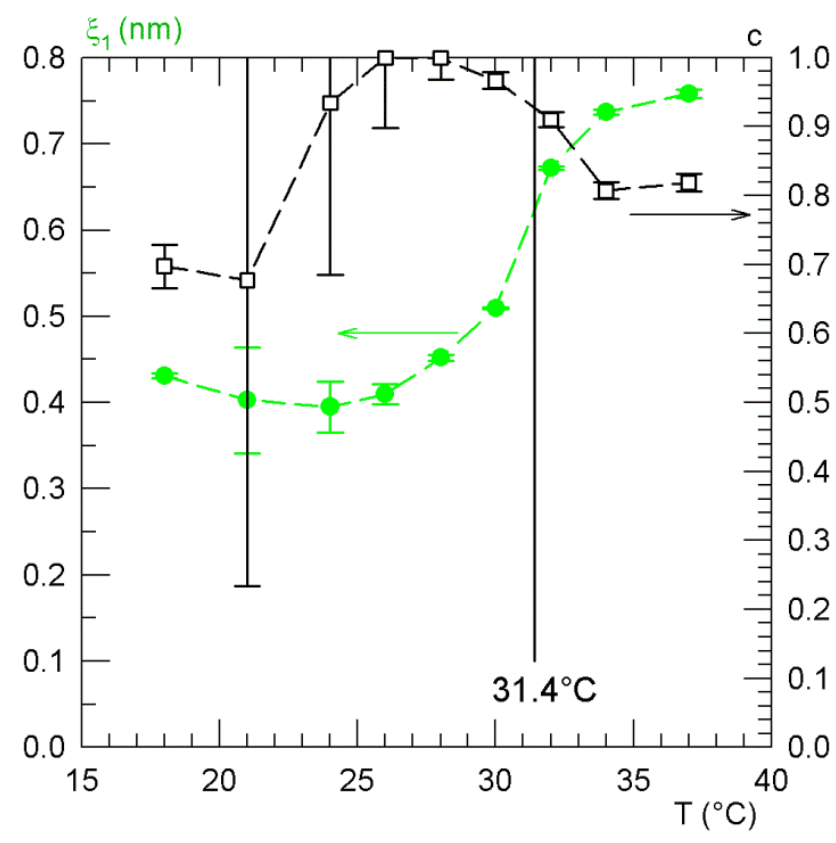

Figure 9. Evolution of the parameters $\xi_{1}$ (left axis) and $c$ (right axis) resulting from the fit with the pseudo-Voigt equation (Equation 3).

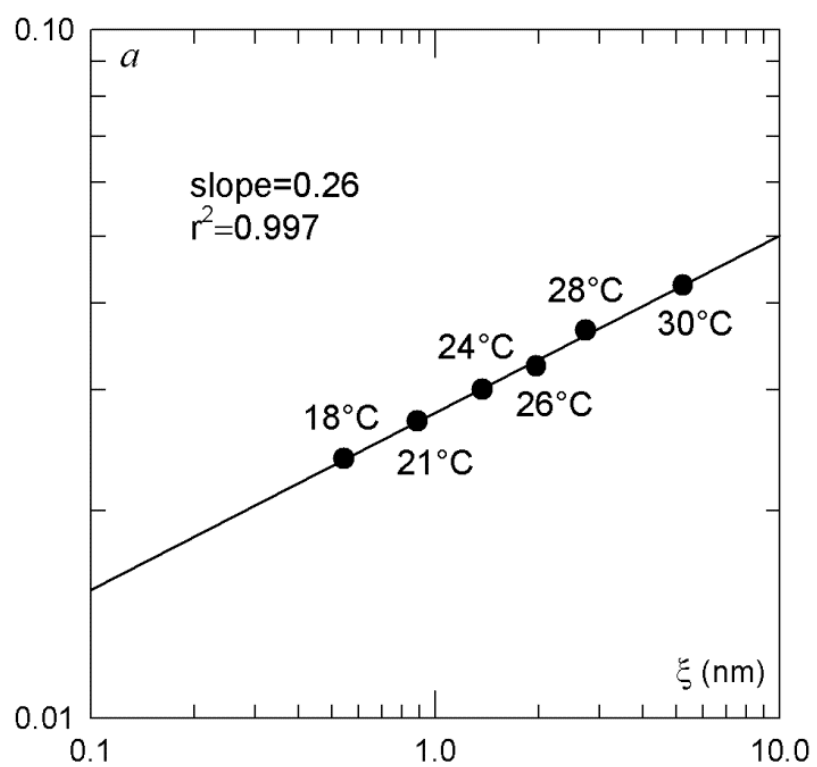

Figure 10. Variation of the pseudo-Voigt intensity $a$ (Equation 3) with the blob size $\xi$ (Equation 1).

Figure 8 shows that the peak height $a$ increases linearly with temperature up to $24^{\circ} \mathrm{C}$ and remains nearly constant above $32^{\circ} \mathrm{C}$. Between 24 and $32^{\circ} \mathrm{C}$, the rate of increase becomes larger. It appears (Figure 10) that $a$ scales as the blob size $\xi$ with an exponent equal to 0.26 . The physical meaning of the value of this exponent is not obvious. Meanwhile, the scaling law suggests that the increase of $a$ 
corresponds to the increase of the number of scatterers resulting from the increase of the size of the T-blobs. Conversely, the peak position $q_{1}$ displays a weak monotonous linear increase (between 5.18 and $5.64 \mathrm{~nm}^{-1}$ ) with temperature up to $34^{\circ} \mathrm{C}$. The values of $q_{1}$ are very similar to that obtained for the different cryogels investigated earlier [25] below and above the critical temperature but slightly larger than the value $\left(5.7 \mathrm{~nm}^{-1}\right)$ reported for a weakly cross-linked pNIPA gel at $40^{\circ} \mathrm{C}$ [19]. The increase of $q_{1}$ (Figure 8) corresponds, in the real space, to a decrease of the distance $d$ between the dehydrated (i.e., without "water cages" around the isopropyl terminal groups in the side-chain) polymer chains. $d$ can be estimated by means of the Bragg equation $d=2 \pi / q_{1}$ from 1.21 to 1.12 $\mathrm{nm}$. As discussed earlier [25], such lengths are less than or nearly twice that of the side chain. It follows that the peak may actually originate from a local packing by means of hydrophobic association of isopropyl groups of two neighbor chains and/or hydrogen bonds between amide groups [33]. Thus, it may be assumed that the scattering object from which this peak originates are the collapsed hydrophobic clusters (or nanopockets) revealed by Ahmed et al. [34] by means of UV Resonance Raman experiments, which are present in the T-blobs.

The weak variation of $q_{1}$ (or $d$ ) with temperature could be attributed to tiny changes in the conformation of the pNIPA chains resulting from the change of hydrogen bonding of water at the $\mathrm{C}=\mathrm{O}$ or $\mathrm{N}-\mathrm{H}$ sites. The strong increase of $a$ (concordant with the increase of $\xi$ ) between 26 and $30^{\circ} \mathrm{C}$ could be related to the abrupt spectral change in the amide (AmI) bands observed between 30 and $40^{\circ} \mathrm{C}$ in the pNIPA nanoparticles investigated in ref. [34], for which the transition temperature is $33^{\circ} \mathrm{C}$. Figures 5, 6 and 8 show that collapsed clusters are present at lower temperatures, between 18 and $24^{\circ} \mathrm{C}$. This feature is consistent with the ones reported in ref. [34]. It is also consistent with the conclusions drawn about the peak intensity in a gel as compared to the cryogel at room temperature [25]. Meanwhile, it is difficult to explain why the values of $\xi$ obtained at $18^{\circ} \mathrm{C}(0.543$ $\mathrm{nm})$ and $21^{\circ} \mathrm{C}(0.886 \mathrm{~nm})$ are smaller than the corresponding value of $d(1.21$ and 1.19 , respectively) deduced from the peak position $q_{1}$. For the dry sample, $q_{1}\left(=5.56 \mathrm{~nm}^{-1}\right)$ is slightly smaller than in the fully collapsed cryogel at $37^{\circ} \mathrm{C}\left(q_{1}=5.63 \mathrm{~nm}^{-1}\right)$. Accordingly, the inter-chain distance would be slightly larger in the dry sample $(1.13$ or $1.03 \mathrm{~nm})$ than in the collapsed aqueous cryogel (1.11 or $1.02 \mathrm{~nm})$. The analysis of the UV Raman resonance spectra of the dry pNIPA led Ahmed et al. [34] to suggest the existence of interchain hydrogen bonding between pendent amides. Conversely, in the collapsed hydrogel, amides seem to be hydrogen bonded to water and not directly to each others. At this point, and because of the very small differences in the values of $d$, it is difficult to go further into this discussion.

Finally, (i), the analysis of the OZ and pseudo-Voigt equation, (ii), of the corresponding parameters $\left(I_{\mathrm{OZ}}(0), \xi\right.$ and $\left.a\right)$, and (iii), their correlation render the origin of the isoscattering point, i.e., the 
existence of a point $\left(q_{i s o}, I_{i s o}\right)$ independent of T, more straightforward. In the $q$-range investigated $\left(q>2 \mathrm{~nm}^{-1}\right)$, the variation of the scattered intensity $I(q, \mathrm{~T})$ is equal to $I_{\mathrm{OZ}}(q, \mathrm{~T})+I_{\mathrm{V}}(q, \mathrm{~T})$. Both functions contain temperature dependent parameters for which the temperature dependence is described by equations that remain the same over a given range of temperature. It follows that $I(q, \mathrm{~T})$ is expressed by a linear combination of two functions, in which case, an isoscattering point $q_{i s o}, I_{i s o}$ is expected [35]. The isoscattering point does no longer exist above $\mathrm{T}_{\mathrm{c}}$ because the temperature dependence of the parameters in $I_{\mathrm{OZ}}(q, \mathrm{~T})$ changes. In the present case, $q_{\text {iso }}$ equals $3.633 \mathrm{~nm}^{-1}$. The physical meaning of this value is still unclear. It must be noted that this isoscattering point does not indicate that the system transforms from one state to another one as generally reported and aforementioned. Here, the isoscattering point results from the fact that the number of nanopockets giving rise to the high- $q$ peak is directly related to the size of the T-blobs (diverging at $\mathrm{T}_{\mathrm{c}}=31.4^{\circ} \mathrm{C}$ ). In the domain of temperature ranging between 32 and $37^{\circ} \mathrm{C}$, i.e., above the temperature of the transition occurring at the molecular level and characterized by the divergence of the $\mathrm{O}-\mathrm{Z}$ parameters, it is still necessary to include an $\mathrm{O}-\mathrm{Z}$ equation to fit the experimental curves (Figures 3 and 4). Meanwhile, the intensity in quite small and the values of $\xi$ vary between 1 and $2.5 \mathrm{~nm}$ (Figure 5). This feature makes sense because the system is still a gel. However, the gel network is different from what it was below $\mathrm{T}_{\mathrm{c}}$ and the isoscattering point vanishes accordingly.

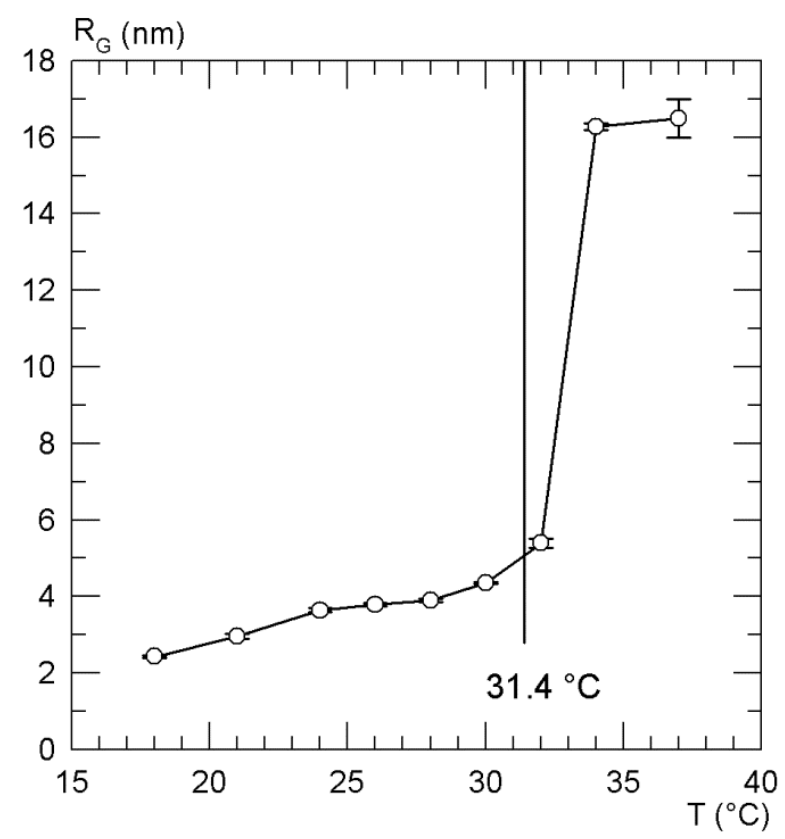

Figure 11. Variation of the Guinier radius of gyration $R_{\mathrm{G}}$ (Equation 2) with temperature. 


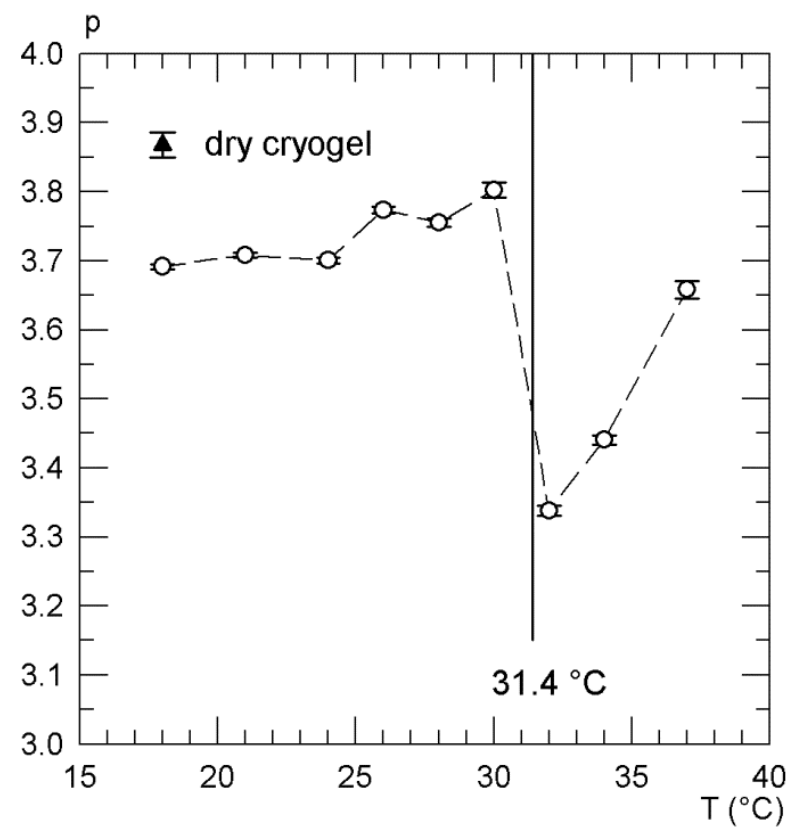

Figure 12. Variation of the exponent $p$ in the power law (Equation 4) resulting from the scattering of the gel surface. The surface fractal dimension $\mathrm{D}_{\mathrm{s}}$ is equal to 6- $p$.

Figures 11 and 12 show that, within the domain of temperature $\left(18-30^{\circ} \mathrm{C}\right)$ investigated above, the parameters related to the equations describing the scattering at lower $q$-values (power law and Guinier equations) do not vary much. Because the Guinier equation describes the solidlike inhomogeneities arising from the cross-links, $R_{\mathrm{G}}$ is supposed to be independent of the temperature. However, as in ref. [15], $R_{\mathrm{G}}$ increases slightly between 18 and $32^{\circ} \mathrm{C}$, i.e., above $\mathrm{T}_{\mathrm{c}}$. It can be noticed that these values, ranging between 2.5 and $5.4 \mathrm{~nm}$ are much smaller than that reported for gels [15, 16]. This feature could be related to the particular method of polymerization (cryopolymerisation) used for cryogels. Assuming a spherical shape for these static inhomogeneities arising from the cross-link regions, their diameter $d_{s t}$ can be evaluated by $d_{s t}=2 R_{G} \sqrt{5 / 3}$. It follows that $d_{s t}$ varies between 6.45 and $13.93 \mathrm{~nm}$ when $\mathrm{T}$ increases from 18 to $32^{\circ} \mathrm{C}$. Between 32 and $34^{\circ} \mathrm{C}, R_{\mathrm{G}}$ jumps and seems to reach a plateau at $34^{\circ} \mathrm{C}\left(R_{\mathrm{G}}=16.5 \mathrm{~nm}\right.$ or $\left.d_{s}=42.6 \mathrm{~nm}\right)$. Also at $32^{\circ} \mathrm{C}$, the exponent $p$ in the power law (Equation 4) drops from 3.80 to 3.34 revealing a sharp increase of the fractal dimension $\mathrm{D}_{\mathrm{s}}$ of the gel surface from 2.20 to 2.66 (Figure 12). This feature could be related to the concept of the crumpled globule state describing the collapse of polymer gels [36] or the protein folding [37] associated to microphase separation. It follows that the radius of gyration $R_{\mathrm{G}}$ measured at $34^{\circ} \mathrm{C}$ could be related to the size of the polymer rich domains (microphases) near cross-linking points.

\subsection{Relation between features observed at nano-and mesoscopic scale by SAXS and}

macroscopic observations. The macroscopic evidence of the physico-chemical phase transition is 
revealed by significant decrease of the sample volume (the volume phase transition) related to the decrease of the degree of swelling or swelling ratio. The swelling ratio $s r$ is generally determined by the mass of water per unit mass of dry gel: $s r=\left(M_{s w}-M_{d r y}\right) / M_{d r y}$. Figure 13 shows the variation of $s r$ for the pNIPA cryogel studied. The amplitude of the jump is mainly related to the swelling ratio at room temperature (the lower the degree of cross-linking, the larger the variation of $s r$ ) in gels [38], in microgels [21] and in cryogels [25]. Further, the degree of cross-linking seems also to influence the shape of the transition [32]. As mentioned in paragraph 2.1., the degree of cross-linking of the present cryogel is quite large since [MBAA]/[NIPA] equals 1/15. Thus, the swelling and the swelling jump is much smaller than for the pNIPA cryogel investigated earlier [25] for which [MBAA]/[NIPA] was equal to $1 / 40$.

Between 18 and $24^{\circ} \mathrm{C}$, the swelling ratio decrease is nearly linear and small. At $26^{\circ} \mathrm{C}$, i.e., at the beginning of the phase transition domain, the swelling ratio begins to decrease more intensively and attains nearly half of its value at $\mathrm{T}_{\mathrm{c}}$. The insert in Figure 13 indicates that the effect of the temperature elevation on deswelling is the strongest near the critical temperature $\left(\mathrm{T}_{\mathrm{c}}=31.4^{\circ} \mathrm{C}\right)$ deduced from the physico-chemical events shown by DSC and SAXS (divergence of the blob size $\xi)$. Because the cryogel is a macroporous gel, it is strongly heterogeneous at the scale of a few or tens micrometers. SAXS data result from the averaging over several macropore (filled with water) and pore walls (the gel investigated) since the size of the beam is about $200 \mu \mathrm{m}$. The swelling measurement yields the total amount of water rejected from the sample, i.e., from the macropore and from the gel walls with no discrimination. In order to get a more precise information about the effect of temperature on the pore wall thickness and on the macropore size distribution, TwoPhoton Fluorescence Microscopy [26] measurements were performed, as mentioned in the Introduction. The value of the mean pore size and of the wall thickness measured at 24, 28 and $34^{\circ} \mathrm{C}$ are indicated on Figure 13. It must be noted that the mean pore size obtained at $28^{\circ} \mathrm{C}$ is larger than that measured at $24^{\circ} \mathrm{C}$ as a result of a significant decrease of the contribution of the smaller pores yielding a non-symmetrical distribution. The diminution of small pores initiating the deswelling of the macroporous gels could result from local collapses of walls for reasons that are not clear yet. On the opposite, the deswelling occuring above $\mathrm{T}_{\mathrm{c}}$, could result from the decrease of the wall size (the gel). The physico-chemical processes, revealed at the mesoscale by the divergence of $\xi$ and the endothermic effect would induce a stress field in the gel. The sharp decrease of the fractal dimension $\mathrm{D}_{\mathrm{s}}$ of the gel surface around $32^{\circ} \mathrm{C}$ could result from the existence of a distribution of local collapsed domains (the crumpled globules mentioned above). The relaxation of the increasing stress could be achieved by the formation of large collapsed domains yielding the second part of the macroscopic volume decrease (Figure 13) going on up to $37^{\circ} \mathrm{C}$. 


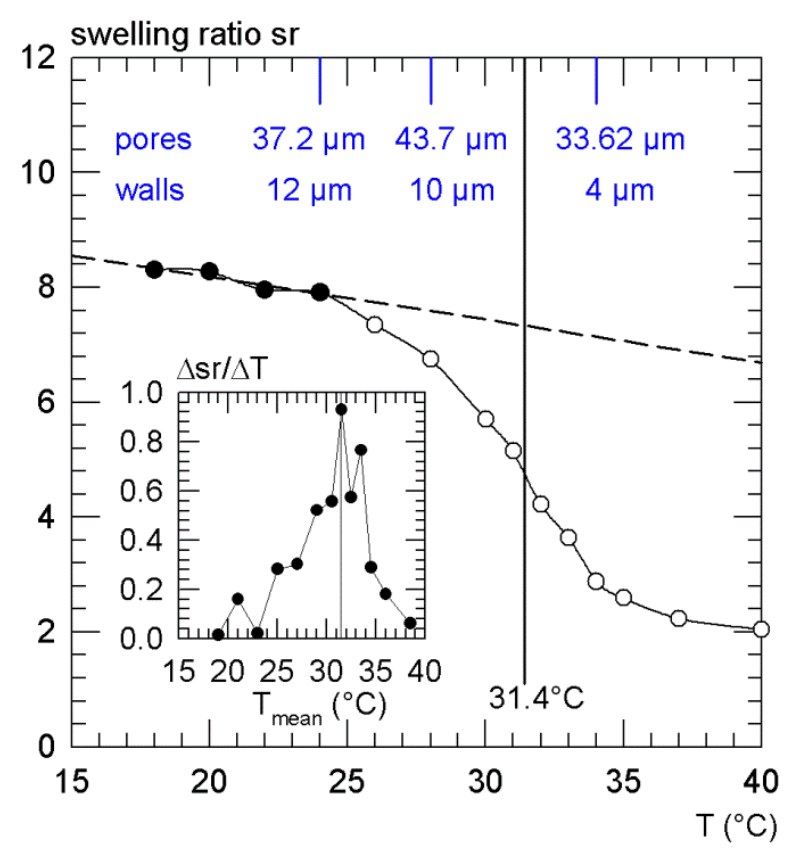

Figure 13. Variation of the swelling ratio with temperature. The insert indicates that the temperature determined by DSC $\left(\mathrm{T}=31.4^{\circ} \mathrm{C}\right)$ corresponds to the inflexion point of the curve $\operatorname{sr}(\mathrm{T})$. The mean macropore diameter and the wall thickness obtained by Two-Photon Fluorescence Microscopy [26] are indicated on the top of the figure.

\section{Summary and conclusion}

The modifications of the structure of a pNIPA gel constituting the walls in a cryogel with temperature were investigated over a broad range of length by SAXS. The experimental curves were fitted by means of a sum of four equations in order to take into account the scattering of each component of the system:

- the scattering of the surface of the gel is fitted with a power law yielding a surface fractal dimension different from 2

- the scattering of the solidlike inhomogeneities arising from the cross-links and characterized by a Guinier equation

- the scattering of the liquidlike or thermal inhomogeneities described by an Ornstein-Zernike equation diverging at a critical temperature as a result of the growth of instabilities induced by "melting" of the bound water molecules surrounding the side chains

- the scattering of hydrophobic nanopockets formed in the T-blobs, resulting from the formation of local inter-chain bonds and yielding the high- $q$ correlation peak fitted by a pseudo-Voigt equation. The analysis of the parameters yielding structural information at the meso and nano-scale are compared with the macroscopic volume change and the thermodynamic effects over the same range of temperature. It is shown that the critical temperature $\mathrm{T}_{\mathrm{c}}=31.4^{\circ} \mathrm{C}$ determined from the divergence of the Ornstein Zernike equation is the same as that of the endothermic effect measured by DSC 
resulting from the "melting" of the water cages surrounding the side chains (dissociation of the hydrophobic solvatation). The evolution of the $\mathrm{OZ}$ parameters $\xi$ and $I_{\mathrm{OZ}}(0)$ with temperature confirms the validity of an Ising model for describing the transition in this pNIPA cryogel. The scaling law between $\xi$ and the intensity $a$ of the chain-chain correlation peak shown here for the first time gives new insights in the origin of the isoscattering point observed up to $T_{c}$. The parameters characteristic of the structure at a larger length scale, i.e., the radius of gyration of the solid-like heterogeneities, $R_{\mathrm{G}}$ and the exponent $p$ of the power law (related to the fractal dimension of the gel surface) begin to change significantly with temperature only above $T_{c}$. This feature suggests that, above $T_{c}$, the volume decrease results from the contraction of the system allowing the relaxation of the stress induced by the conformational changes (physico-chemical effect) occurring below $\mathrm{T}_{\mathrm{c}}$. Further investigations are in progress in order to study the influence of the degree of cross-linking on these mechanisms.

\section{Acknowledgements}

Preparation of the cryogels investigated was performed in the context of the FP6-Network of Excellence: EXPERTISSUES, "Novel Therapeutic Strategies of Tissue Engineering of Bone and Cartilage Using Second Generation Biomimetic Scaffolds”. Partial financial support by CICYTMAT2007-63355 is acknowledged. The authors are grateful to the ESRF, Grenoble, for access to the French CRG beamline D2AM (proposal No.0201702) and they acknowledge the help of its technical staff, Jean-François Berar, Nathalie Boudet, Bernard Caillot, Stephan Arnaud. The authors wish to thank Isabelle Grillo (ILL) for her help in the DSC measurements and Jean-Louis Chemin (SIMAP) for the design of the furnace used for the SAXS measurements.

\section{References}

(1) Hirokawa, T.; Tanaka, T. J. Chem. Phys. 1984, 81, 6379-6380.

(2) Matsuo, E. S.; Tanaka, T. J. Chem. Phys. 1988, 89, 1695-1703.

(3) Pelton, R. Adv. Colloid Interface Sci. 2000, 85, 1-33.

(4) Kausar, N.; Chowdhry, B. Z.; Snowden, M. Microgels from Smart Polymers. In Smart Polymers: Applications in Biotechnology and Biomedicine; Galaev, I.; Mattiasonn, B. CRC Press, 2007; pp. 138-169

(5) Okay, O. Macroporous Hydrogels from Smart Polymers. In Smart Polymers: Applications in Biotechnology and Biomedicine; Galaev, I.; Mattiason, B. CRC Press, 2007; pp. 269-293.

(6) Lozinsky, V. I. Russ. Chem. Bull. 2008, 57, 1015-1032.

(7) Lozinski, V. I.; Plieva, F. M.; Galaev, I. Y.; Mattiason, B. Bioseparation 2002, 10, 163-188.

(8) Lozinsky,V. I.; Galaev, I. Y.; Plieva, F.M; Savina, I.N.; Jungvid, H.; Mattiasson, B. Trends in Biotechnology. 2003, 21, 445-451. 
(9) Plieva, F. M., Karlsson, M.; Aguilar, M.-R.; Gomez, D.; Mikhalovsky, S.; Galaev, I. Y. Soft Matter 2005, 1, 303-309.

(10) Plieva, F.; Huiting, X.; Galaev, I. Y.; Bergenståhl, B.; Mattiasson, B. J. Mater. Chem 2006, $16,4065-4073$.

(11) Plieva, F.M.; Galaev, I. Y.; Mattiasson, B. J. Sep. Sci. 2007, 30, 1657-1671.

(12) Bölgen, N.; Plieva, F.; Galaev, I. Y.; Mattiasson, B.; Piskin, E. J. Biomater. Sci. Polymer Edn. 2007, 18, 1165-1179.

(13) Arndt, K.-F.; Krahl, F.; Richter, S.; Steiner, G. In Hydrogel Sensor and Actuators: Engineering and Technology; Gerlach, G., Arndt, K.-F., Eds.; Springer Series on Chemical Sensors and Biosensors, vol. 6; Springer-Verlag: Berlin-Heidelberg 2009; pp 69-136.

(14) Shibayama, M. Bull. Chem. Soc. Jpn. 2006, 79, 1799-1819.

(15) Shibayama, M.; Tanaka, T.; Han C. C. J. Chem. Phys. 1992, 97, 6829-6841.

(16) Liao, G.; Xie, Y.; Ludwig, K. F.; Bansil, R.; Gallagher, P. Phys. Rev. E 1999, 60, 4473-4481.

(17) Norisuye, T.; Kida, Y.; Masui, N.; Tran-Cong-Miyata, Q.; Maekawa, Y.; Yoshida, M.; Shibayama, M. Macromolecules 2003, 36, 6202-6212.

(18) Koizumi; S.; Monkenbusch, M.; Richter, D.; Schwahn, D.; Farago, B. J. Chem. Phys. 2004, $121,12721-12731$.

(19) Kosik, K.; Wilk, E.; Geissler, E.; Laszlo, K. Macromolecules 2007, 40, 2141-2147.

(20) Hirokawa, Y.; Okamoto, T.; Kimishima, K.; Jinnai, H.; Koizumi, S.; Aizawa, K; Hashimoto, T. Macromolecules 2008, 41, 8210-8219.

(21) Kratz, K.; Hellweg, T.; Eimer, W. Polymer 2001, 42, 6631-6639.

(22) Fernandez-Barbero, A.; Fernandez-Nieves, A.; Grillo, I.; Lopez-Cabarcos, E. Phys. Rev. E 2002, 66, 051803.

(23) Seelenmeyer, S.; Deike, I.; Rosenfeldt, S.; Norhausen, Ch.; Dingenouts, N.; Ballauff, M.; Narayanan, T.; Linder, P. J. Chem. Phys. 2001, 114, 10471-10478.

(24) Karg, M.; Wellert, S.; Pastoriza-Santos, I.; Lapp, A.; Liz-Marzan, L. M.; Hellweg, T. Phys. Chem Chem. Phys. 2008, 10, 6708-6716.

(25) Perez, P.; Plieva, F.M.; Gallardo, A.; San Roman, J.; Aguilar, M.R.; Morfin, I.; EhrburgerDolle, F.; Bley, F.; Mikhalovsky, S.; Galaev, I. Y.; Mattiasson, B. Biomacromolecules. 2008, 9, 66-74.

(26) Chalal, M.; Ehrburger-Dolle, F.; Morfin, I.; Vial, J.-C.; Aguilar de Armas, M.-R.; San Roman, J.; Bolgen, N.; Piskin, E.; Ziane, O.; Casalegno, R. Macromolecules 2009, 42, 2749-2755.

(27) Vargas Pereira, F.; Merlo, A. A.; Bley, F.; Morfin, I.; Ritter, O. M.; Pesce da Silveira, N.; Ehrburger-Dolle, F. Liquid Crystals 2008, 35, 299-313.

(28) Dewettinck, K.; Foubert, I.; Basiura, M.; Goderis, B. Cryst. Growth Des. 2004, 4, 1295-1302. 
(29) Nicolai, T.; Pouzot, M.; Durand, D.; Weijers, M.; Visschers, R. W. Europhys. Lett. 2006, 73, 299-305.

(30) Dubois, E.; Cabuil, V.; Boué, F.; Perzynski, R. J. Chem. Phys. 1999, 111, 7147-7160.

(31) Gibaud, T.; Stradner, A.; Oberdisse, J.; Lindner, P.; Pedersen, J. S.; Oliveira, C. L. P.; Schurtenberger, P. arXiv:0901.4077v1 [cond-mat.soft] 26 Jan 2009.

(32) Li, Y.; Tanaka, J. J. Chem. Phys. 1989, 90, 5161-5166.

(33) Cho, E. C.; Lee, J.; Cho, K. Macromolecules 2003, 36, 9929-9934.

(34) Ahmed Z.; Gooding E. A.; Pimenov, K. V; Wang, L.; Asher, S. A. J. Phys. Chem. B 2009, $113,4248-4256$.

(35) Panda, D.; Datta, A. Appl. Spectrosc. 2008, 62, 341-344.

(36) Grosberg, A. Yu.; Nechaev, S. K. Macromolecules 1991, 24, 2789-2793.

(37) Dewey, T. G. Fractals in molecular biophysics; Oxford University Press, 1997; 44-49.

(38) Shibayama, M.; Morimoto, M.; Nomura, S. Macromolecules 1994, 27, 5060-5066. 